\title{
Living organ donors face financial barriers: A national reimbursement policy is needed
}

\section{Scott Klarenbach, Amit X. Garg, Sorina Vlaicu}

$\mathrm{K}$ idney transplantation from living donors is an established treatment for end-stage renal disease: it increases life expectancy, improves quality of life and is less costly than dialysis. In Canada, the growth of solid-organ transplantation over the past decade has primarily been attributable to increases in living organ donation, for which rates have doubled within the past decade. ${ }^{1}$ Nevertheless, waiting lists continue to grow, and further strategies to increase organ donations from living donors continue to be explored. ${ }^{2}$ Eliminating barriers to donation is one way to increase donors. Currently in this country, there are economic disincentives to donors that, in addition to being unfair, may limit rates of organ donation and need to be addressed with a national policy.

The economics of living kidney donation have been well described from the perspective of the recipient and health care payer: one living kidney donation is estimated to result in a net increase of 2 to 3.5 quality-adjusted life-years, and a net health care savings of $\$ 100000 .{ }^{2}$ The economic impact to the donor, on the other hand, is infrequently considered, but is best understood by first considering all possible direct and indirect (productivity) costs incurred. Direct costs include all resources consumed from the perspective of the donor (which may not involve a direct monetary transaction), including travel for tests, appointments and hospital admission; accommodation; long-distance telephone charges; and incidental medical costs such as fees for medications after discharge. Indirect costs consist of the economic consequences of lost or impaired ability to work or engage in leisure activities, such as lost income and household costs related to domestic maintenance and chores as well as to dependent care.

The frequency and magnitude of these costs are not well described. The existing literature likely underestimates true costs and suffers from the retrospective nature of most reports of donor costs: lengthy time frames for patient recall, low response rates and incomplete capture of all the relevant costs. Nonetheless, it is clear that many donors are adversely affected by these costs. In one follow-up study, financial hardship or significant financial burden was reported by $23 \%$ of people who donated a kidney. ${ }^{3}$ In other examples, $53 \%-$ $99 \%$ of donors experienced costs due to travel and accommodation in 2 North American studies, ${ }^{4,5}$ and $14 \%-30 \%$ lost income (averaging, in 2004 dollars, as much as $\$ 4410$ ). ${ }^{6,7}$

Although the magnitude of these costs may not seem dramatic to some, the context in which they occur deserves consideration. Biological relatives and spouses make up the majority of living donors, who may already be burdened financially by the chronic medical illness of a family member. In a single-centre study involving 133 potential donors to a family member, $24 \%$ did not donate because of the anticipated financial hardship. ${ }^{8}$ This same study indicated that recipients with higher incomes were more likely to receive a kidney from a living donor, which suggests that household financial status may influence which recipients receive a living-donor, as opposed to a deceased-donor, kidney. A similar pattern of higher aggregate income level for those receiving a kidney from a living versus a deceased donor exists in Canada (unpublished data from the Canadian Organ Replacement Registry), and it is a reasonable assumption that economic consequences pose a larger burden to potential donors with a lower income. The existence of financial barriers to potential organ donors clearly runs contrary to our objective of increasing rates of organ donation in Canada.

\section{In one centre, $24 \%$ of pa- tients' relatives did not do- nate because of anticipated financial hardship.}

Some countries, such as Hungary, Portugal, Slovakia and Turkey, do not permit any form of compensation for donors. This may stem from a desire to avoid a free or black market for organs. However, recent policies addressing reimbursement of the financial consequences incurred by donors have emerged internationally. The World Medical Association and the American Medical Association Council on Ethics and Judicial Affairs make a clear distinction between reimbursement of the expenses incurred through the donation process, which is expressly deemed permissible, and a market where payment for an organ results in financial gain.

Reimbursement is allowed implicitly in some countries, including Canada, whereas others have adopted explicit policies. In France, for example, transplant centres are required to reimburse donors for travel and accommodation expenses; and in the United Kingdom, the National Health Service is permitted, though not required, to reimburse lost wages as well as travel and accommodation costs.

Currently Canada does not have a national unified strategy to reimburse living organ donors. Before devising a strategy, it is important to identify existing services and infrastructure to deliver such a policy. Current federal initiatives include employment insurance and short-term disability as well as the tax credit for medical expenses. Provincial initiatives include coverage for medical services, limited travel coverage in some 
provinces (Newfoundland and Labrador, New Brunswick, Prince Edward Island and northern Ontario) and paid-leave programs (Saskatchewan). Assistance from nonprofit organizations such as the Kidney Foundation of Canada is potentially available. However, the requirements necessary to receive employment insurance and benefits delivered through tax credits may work to the disadvantage of people who work in alternative arrangements or have a lower income, and all existing programs are limited in scope and availability.

In a survey of key Canadian informants in the field of organ transplantation - sources working in transplant centres, provincial governments, professional associations, nongovernmental organizations and charities active in transplantation in Canada, prioritized according to their experience in working directly with living donors on issues of reimbursement - consensus was reached that reimbursing donors for incurred expenses is desirable. Indeed, a comprehensive reimbursement program is being considered in British Columbia, and planning committees working to improve financial support for living donors exist in Alberta, Quebec and Nova Scotia. Most informants held the opinion that existing infrastructure could be used to impliment such a program, although additional wherewithal, especially human resources, would be required.

Political, social, regulatory and technical issues may each influence the creation and implementation of a donor reimbursement policy; cost, however, is a major consideration. Although the costs incurred through kidney donation cannot be gauged with certainty, most estimates have ranged from $\$ 1045$ to $\$ 5225 ;{ }^{6}$ in British Columbia, reimbursements to donors are estimated at the midpoint of this range. Allowing for growth in rates of donation, the anticipated annual national costs for such a reimbursement program for living donors of kidneys is $\$ 560$ ooo- $\$ 2.8$ million. In contrast, the cost in 2000 of providing dialysis therapy in Canada was an estimated $\$ 9.4$ billion. ${ }^{9,10}$ Each kidney donation is expected to save the health care system about $\$ 100000^{2}$ and provide an additional 2 quality-adjusted life-years. If a $25 \%$ overhead for administering a national reimbursement program is assumed, even a 10\% increase in kidney donations because of the removal of economic disincentives may result in neutral or net negative costs from a societal perspective.

We suggest that a national reimbursement program with federal funding and coordination but provincial implementation would be the best option. The program should include strong safeguards against the commercialization of organs and mechanisms not only for coordinating benefits and adjusting for regional differences in cost of living but also for cost control and promotion of provincial add-ons. Pilot programs would allow a full assessment of the costs and benefits of such a program before widespread implementation, which may allay fears of high program costs.

In conclusion, we rely on altruistically motivated organ donors to improve the health of those with chronic disease. Although we can only strive to attenuate the medical and psychosocial risks associated with donation, ${ }^{11}$ it is entirely possible to eliminate the economic risks for Canadian organ donors completely, through legally and ethically acceptable financial reimbursement. Not only is implementation of such a strategy just, but the removal of this barrier is an obvious step to encourage and recognize living donation.

From the Department of Medicine, Division of Nephrology, University of Alberta, and the Institute of Health Economics, Edmonton, Alta. (Klarenbach), and the Departments of Political Science (Vlaicu) and of Epidemiology and Biostatistics (Garg, Vlaicu), Division of Nephrology (Garg), University of Western Ontario, London, Ont.

Competing interests: None declared.

Contributors: Scott Klarenbach drafted the manuscript. All authors contributed equally to the conceptual content and critical revision, and approved the final submission.

Acknowledgements: We thank Katie Clark, Todd Dempster and Bob Yang for their help with data collection and analysis, and the Donor Nephrectomy Outcomes Research (DONOR) Network.

All authors were consultants for a National Consensus Conference on Living Kidney Donation, hosted 2006 Feb I0-I2 by the Canadian Council for Donation and Transplantation, an independent, not-for-profit corporation.

This work was supported by the Canadian Council for Donation and Transplantation. Grant support was received from the Canadian Institutes of Health Research (CIHR). Neither sponsor had any role in the study design; data collection, analysis or interpretation; or report composition. Amit Garg is supported by a Clinician Scientist Award from CIHR.

\section{REFERENCES}

I. McAlister VC, Badovinac K. Transplantation in Canada: report of the Canadian Organ Replacement Register. Transplant Proc 2003;35:2428-30.

2. Whiting JF, Kiberd B, Kalo Z, et al. Cost-effectiveness of organ donation: evaluating investment into Donor Action and other donor initiatives. Am J Transplant 2004;4:569-73.

3. Schover LR, Streem SB, Boparai N, et al. The psychosocial impact of donating a kidney: long-term follow-up from a urology based center. J Urol 1997;157:1596-6or.

4. Vlaovic PD, Devins GM, Abbey S, et al. Psychosocial impact of renal donation. Can JUrol I999;6:859-64.

5. McCune TR, Armata T, Mendez-Picon G, et al. The Living Organ Donor Network: a model registry for living kidney donors. Clin Transplant 2004;18(Suppl I2):33-8.

6. Johnson EM, Anderson JK, Jacobs C, et al. Long-term follow-up of living kidney donors: quality of life after donation. Transplantation 1999;67:717-21.

7. Lyons K, Shallcross J, Bakran A. Eight years experience of reimbursement costs associated with an active living donor programme [abstract]. Transplantation 2004;78:2-3.

8. Knotts RS, Finn WF, Armstrong T. Psychosocial factors impacting patients, donors, and nondonors involved in renal transplant evaluation. Perspect 1996;15:II-23.

9. Canadian Organ Replacement Register. Preliminary report for dialysis and transplantation 2002. Ottawa: Canadian Institute for Health Information; 2003. Available: http://secure.cihi.ca/cihiweb/dispPage.jsp?cw_page=reports_corr2002prelim_e (accessed 2006 Feb 9).

Io. Lee $\mathrm{H}$, Manns B, Taub K, et al. Cost analysis of ongoing care of patients with endstage renal disease: the impact of dialysis modality and dialysis access. Am J Kidney Dis 2002;40:61I-22.

II. Abecassis M, Adams M, Adams P, et al. Consensus statement on the live organ donor. JAMA 2000;284:2919-26.

Correspondence to: Dr. Scott Klarenbach, II-IO7 Clinical Sciences Building, 8440 II 2 th St., University of Alberta, Edmonton $A B$ T6G 2G3; fax 780 407-7878; scott.klarenbach@ualberta.ca 